\title{
Mapping Real-World to Online Vulnerability in Young People with Developmental Disorders: Illustrations from Autism and Williams Syndrome
}

\author{
Emma Lough • Emma Flynn • Deborah M. Riby
}

Received: 24 March 2014 / Accepted: 26 June 2014 / Published online: 11 July 2014

(C) Springer Science+Business Media New York 2014

\begin{abstract}
The Internet poses a new kind of threat, especially for those individuals already vulnerable in society. The current paper draws on the social phenotypes associated with autism spectrum disorder (ASD) and Williams syndrome (WS) to propose that individuals with some developmental disorders face an elevated level of risk whilst online. Many individuals with ASD struggle to maintain social relations and are frequent users of screen-based technology, using the Internet to seek out social connections. Similarly, individuals with WS harbour an extreme pro-social drive to interact with others, both familiar and unfamiliar, and experience difficulties understanding the subtle nuances of social behaviour. Specific risk factors such as these are used to illustrate the case for online vulnerability in developmental disorders.
\end{abstract}

Keywords Social vulnerability $\cdot$ Online $\cdot$ Autism $\cdot$ Williams syndrome

\section{Introduction}

The vulnerability and safety of children and young people is a prominent issue for the parents, media and government of today. High-profile cases of child victimization and abuse have nurtured fear within society about the safety and resilience of young people (Mitchell et al. 2011). Concern regarding vulnerability and risk has recently been extended to Internet conduct, with cyber bullying, trolls and online

E. Lough $(\bowtie) \cdot$ D. M. Riby

Department of Psychology, Durham University, Science

Laboratories, South Road, Durham DH1 3LE, UK

e-mail: e.f.lough@durham.ac.uk

E. Flynn

School of Education, Durham University, Durham, UK grooming posing a new type of risk to young people (Livingstone et al. 2011). The 'EU Kids Online' survey, which interviewed 25,000 children and their parents throughout Europe (Livingstone et al. 2011), found that young people with an intellectual or physical disability face an elevated level of risk compared to others. Such findings reinforce the recommendations of the UK 'Children Go Online' survey (Livingstone and Bober 2005), which called for in-depth, targeted research on the Internet conduct of vulnerable minority groups, specifically highlighting ethnic minorities and individuals with disabilities as priorities for future research. Yet, despite these findings and recommendations, there has been little research to advance our knowledge about the vulnerability of these groups in an online environment (Whittle et al. 2013a). This current paper aims to use what is known about the social profiles of individuals with developmental disorders (namely autism spectrum disorder (ASD) and Williams syndrome (WS)), as well as our knowledge of offline social vulnerability, to inform predictions about the vulnerability of these cohorts online, in order to stimulate the critical research and debate for action in this area.

\section{Autism Spectrum Disorder and Williams Syndrome}

Whilst vulnerability and resilience are relevant to all young people, autism spectrum disorders (ASD) and Williams syndrome (WS) are developmental disorders that offer case illustrations showing when the interaction between social characteristics and online/offline vulnerability are especially pertinent. As detailed in subsequent sections, these two disorders have been chosen as they are characterised by atypicalities of social behaviour, but the nature of those atypicalities varies across the two disorders. Importantly, the impact of the atypicality has implications for everyday social functioning in both 
groups. The reasons for postulating that offline-online social vulnerability is critical in these groups are as follows:

\section{Autism Spectrum Disorders}

ASDs are a set of lifelong neuro-developmental disorders, typically characterised by a triad of impairments in the domains of communication, social interaction and restricted, repetitive behaviours (APA 2000). Thus, many individuals who are functioning on the autism spectrum have difficulty interpreting social situations and responding appropriately to them (Smith et al. 2010). These difficulties have implications for face-to-face interaction; for example, individuals may miss communicative cues (Rump et al. 2009). As a consequence of the array of social difficulties and possible intellectual impairments, individuals who have autism represent a highly socially vulnerable cohort in their real (offline) world (Howlin et al. 2004).

It remains unclear how the social profile associated with functioning on the autism spectrum and resulting vulnerability might manifest online. Whilst online and offline worlds are becoming more integrated, it may be that environments that rely more on virtual interactions (online environments) make different interactional demands to environments with less, or no virtual interactions; but what effect do these differing environments have for individuals who are functioning on the autism spectrum? Online platform offers individuals with autism an alternative method of engaging in social interaction, which may be appealing due to the diminished levels of social presence, reciprocity and social anxiety, whilst also drawing on frequent strengths and interests in screen-based technology (Mazurek 2013). Conversely, impairments associated with ASD could lead to inappropriate interactions styles online, as they do offline (Happé 1999), as social acuity is still required in conversations online as it is offline. A dialogue of the similarities and differences that is suggested for the offline-online interactional environments of individuals who are developing typically will be provided to inform discussion of the proposed online vulnerability faced by individuals with ASD.

\section{Williams Syndrome}

Williams syndrome (WS) is a rare genetic neurodevelopmental disorder, caused by the microdeletion of 2528 genes on chromosome 7q11.23 (Hillier et al. 2003). Characteristics of WS include mild-moderate intellectual impairment (estimated mean IQ of 50-60; Searcy et al. 2004) and a distinct social profile, notably, a hyper-sociable behavioural phenotype (Järvinen et al. 2013). This latter characteristic refers to an exaggerated desire to interact with othersboth familiar and unfamiliar people (Jones et al. 2000; Jawaid et al. 2012). During such interaction, it has been suggested that some individuals with WS display atypicalities of social communication and behaviour, for example, prolonged gaze behaviour to faces, especially the eye region (Riby and Hancock 2008). Their verbosity masks their level of intellectual impairment, allowing an easy flow of conversation but at a superficial level (Mervis et al. 2000). This relative proficiency hides an array of subtle deficits and atypicalities of evaluating complex emotional prosody during interactions (Pinheiro et al. 2011). These characteristics can occur in parallel with aspects of psychopathology, such as highly prevalent anxiety as the main mental health concern (Stinton et al. 2010). Indeed, individuals with WS who show the highest anxiety also show more severe problems with everyday social behaviours (Riby et al. 2013a, b).

As with ASD, it remains unclear how this social profile may be exhibited in an online environment, and the consequent level of risk that these traits pose when interacting online. What is known is that individuals with WS are considered highly vulnerable in the offline environment (Jawaid et al. 2012). Based on what we know about the level of transference in vulnerable typically developing young people (Whittle et al. 2013a), there is reason to postulate that this vulnerability could be matched if not intensified during online interactions for individuals with WS. In order to pursue this line of argument, we must first acknowledge what it means to be vulnerable in the offline environment.

\section{Social Vulnerability}

Due to the substantial social atypicalities in the groups discussed above, as well as our interest in the social online conduct of these groups, it is social vulnerability that is of particular interest in this context. Social vulnerability specifically refers to "the disadvantages faced by an individual while he or she endeavours to survive as a productive member of the society" (Jawaid et al. 2012 p335), encompassing bullying (Fox and Boulton 2005), abuse (Sidebotham 2013), victimization (Fisher et al. 2013) and social exclusion (Hofvander et al. 2009). When considering social vulnerability as an outcome, the relation between the contribution of 'risk' and 'protective' factors must be considered (Whittle et al. 2013b). The existing body of literature has established a common understanding that risk factors constitute a characteristic, a situation or a combination of both that result in a heightened probability that an individual will experience harm (Masten and Powell 2003). Conversely, the consensus of opinion on protective factors revolves around definitions that acknowledge their protective influence in minimising the impact incurred by the risk (Blum et al. 2002). Rather than a single risk factor, young people tend to hold a socially vulnerable position due to the interaction between several risk factors, which 
occur in lieu of sufficient protective factors (Dixon et al. 2009). It is important to reflect on how this information can help make predictions about online vulnerability, before considering how using the profiles of ASD and WS as case examples, we can highlight risk factors that elevate levels of online vulnerability.

\section{Interaction Between Online and Offline Vulnerability}

With the rise of interactive technology, most notably the internet, the social environment in which young people interact has expanded to encompass a virtual world of communication. The portability of devices that allow access to the internet such as iPads, mobile phones, and Kindles, permit constant communication and accessibility. It is estimated that over $80 \%$ of $5-15$ year olds have access to the internet at home (European Commission 2008), with as many as $31 \%$ having access in their bedroom and $66 \%$ having a mobile phone by their tenth birthday (Ofcom 2010). This has led to a debate on the extent to which there is a distinction between one's online and offline existence, and in turn, the level of transference between offline and online existence (Child Exploitation and Online Protection Centre 2010).

It has been argued that the characteristics of those individuals considered to be most vulnerable offline can be used to make predictions regarding their vulnerability online (Whittle et al. 2013b). Numerous studies have identified qualities such as immaturity (Olson et al. 2007), agreeableness (Talbot et al. 2003) and mental health problems (Mitchell et al. 2007) as precursors to offline social vulnerability. It has been suggested that these offline characteristics shape how an individual presents him- or herself to others online (CEOP 2010). For example, those with fewer and weaker social relationships in the offline world may seek to form relationships online to compensate for this void (Mesch 2001). As suggested above, the online and offline platforms could be so complexly intertwined that they cannot be viewed in isolation.

Similarities between the demographics of offline and online vulnerable populations have also been identified. For instance, as with traditional 'offline abuse', girls have been found to be targets of online sexual solicitations almost twice as often as boys (Mitchell et al. 2007). This supports the argument that similar characteristics and profiles precede vulnerability both online and offline. However, the integrity of these findings has been called in to question as research on 'sexual solicitations' does not solely encompass dangerous predatory behaviour from older adults but includes advances from peers (Whittle et al. 2013b). This means that the motivations behind these solicitations and the danger they pose to vulnerable individuals remain unclear. Likewise, the stigma attached to boys being sexually abused may repress male victims from reporting these experiences, meaning they could be underrepresented in the majority of prevalence estimates (O'Leary and Barber 2008). Without clear estimates of the rates of under reporting, it is unfounded to use such prevalence rates to suggest that the vulnerable population is the same both online and offline. Rather, the data highlight that females are more likely to report inappropriate solicitations, both online and offline, than males - although this in itself remains speculative.

However, Whittle et al. (2013a), among others, including Suler (2004), propose that the fundamental differences between the offline and online environment are so substantial that each environment needs to be examined separately in order to accurately understand vulnerability. For example, the disinhibition effects experienced by some people when interacting online could be fundamentally important when considering online grooming behaviour (European Online Grooming Project et al. 2012). According to Suler (2004), anonymity, invisibility and minimal authority present all feed into how people interact online. Suler (2004) acknowledged that disinhibition can be benign or indeed, even be positive by helping to facilitate the discussion of thoughts on difficult issues. However, it can also be toxic and used to justify the use of criticism or threatening behaviour.

Whilst this holds some validity, the definition of grooming appears to remain constant irrespective of the environment, with only the techniques used to pursue this offence differing (Whittle et al. 2013a). Craven et al. (2006, p. 287) defined grooming as "a process by which a person prepares a child, significant adults and the environment for the abuse of this child. Specific goals include gaining access to the child, gaining the child's compliance and maintaining the child's secrecy to avoid disclosure". Therefore, it could be that the online and offline environments share similar risk factors to vulnerability, and the impact this vulnerability has on the individual can be seen as comparable in both; with the methods used for pursuit in exploiting this vulnerability differing (Whittle et al. 2013a). Critically, we can use what we know about offline risk factors, along with the social phenotypes of ASD and WS, to offer suggestions on key factors that could place some individuals with developmental disorders in a vulnerable position online. The essential component here is that not all individuals who are developing typically, or indeed all individuals who have ASD or WS, will be placed in a vulnerable position online (e.g., it is not inevitable) but an awareness and a call for an understanding of the key issues is required at this time when the use of online social engagement is increasing.

\section{Risk Factors for Vulnerability}

For children following an atypical developmental trajectory, social vulnerability and the possible consequences of social 
vulnerability present a sizeable risk (Jawaid et al. 2012). When translated to the online world, this population are vulnerable as they may be unable to identify the inappropriate advancements of others, and may lack the intellectual capacity to evaluate why their own exploits may place them in a vulnerable situation (Whittle et al. 2013b). There are several risk factors to online social vulnerability, and the subsequent section highlights factors considered to be most congruent with having a developmental disorder, as illustrated by ASD and WS. We present important avenues for future research, which will allow us to enhance our understanding of online vulnerability in individuals with developmental disorders.

\section{Trust}

High levels of trust towards strangers have been implicated as a risk factor to vulnerability for young people with WS (Riby et al. 2013a, b). It has been suggested that children as young as 5 years who are developing typically have the ability to use their judgement of facial expressions to decipher levels of trustworthiness to an accurate level (Willis and Todorov 2006). However, the stranger-danger awareness literature has emphasized that many individuals with developmental and intellectual disabilities display elevated levels of stranger trust (Pinkham et al. 2008), which remain after their age-matched typically developing peers have learnt to make informed judgements of trustworthiness.

Adults with WS engage in a degree of indiscriminate trust and increased social approach behaviour, suggesting that even as adults, this cohort has yet to refine their ability to make trustworthiness judgements (Fisher 2013). On approachability tasks, Hanley et al. (2013) found that 'do not trust' judgements were especially difficult for WS participants (aged between 7 years 2 months and 38 years 10 months) to correctly identify when compared to typically developing controls matched on verbal ability or chronological age. Individuals with WS have difficulty making sense of the socio-communicative cues that help guide these judgements of trust. This difficulty to discriminate levels of trustworthiness, combined with their strong motivation to engage in social encounters (Frigerio et al. 2006) and reduced inhibitory control (Little et al. 2013), often leaves individuals with WS in a socially vulnerable position (Jawaid et al. 2012). However, the majority of this research has used methods concerning the emotional processing of faces, which may not map onto more naturalistic environments. Furthermore, it may not be possible to draw transferable conclusions between these data and an online environment, where faces have diminished presence. Thus, it remains unclear whether individuals with WS extend this trust behaviour to the text presented online, and also what level of intellectual capacity and emotional awareness they have concerning potential deception. Indeed, it is known that individuals with WS struggle with the subtle nuances of social interaction such as telling the difference between a joke and a lie (Sullivan et al. 2003). If it is hard for individuals with WS to make this distinction in face-to face-communication, it may be equally hard, or even harder, online. Such an area is ripe for future exploration.

Involvement of Parents

Fisher et al. (2012) devised the Social Vulnerability Questionnaire for use with individuals who had WS, which outlined four key contextual facilitators: risk awareness, social protection, perceived vulnerability and parental independence. One of the most significant correlates of social vulnerability for individuals with WS was parental independence. Parents of young people with WS were more likely to leave them unsupervised for prolonged periods of time and allow their child to spend unsupervised time with members of the opposite sex in the offline world compared to parents of children with ASD and parents of children with Down syndrome. This reduced level of parental involvement is of concern when considering the findings of the EU Kids Go Online survey (Livingstone et al. 2011), which noted that young people with disabilities experienced an elevated contact risk, meaning they were more likely than other groups to arrange meetings with people they have met online. This suggests that, not only are individuals with WS more likely to arrange meetings online, but these meetings may go undetected by parents due to the individuals' higher levels of parental autonomy. Further research is needed on the relationship between parental autonomy and contact risk in vulnerable young people.

\section{Social Isolation}

Social isolation is also thought to be a significant precursor to social vulnerability (Jawaid et al. 2012). The lack of support networks mean that socially isolated individuals not only miss the protective influence of significant others, but it also minimises their opportunity to confide in someone about any untoward behaviour they experience, which has significant repercussions on their ability to cope (Whittle et al. 2013b). Such dynamic reinforces the cycle of vulnerability. Individuals with ASD have been widely reported to experience social isolation (Billstedt et al. 2005), and likewise, up to $73 \%$ of adults with WS have been found to demonstrate social isolation as adults, with difficulties in relationship formation and maintenance (Davies et al. 1998). Ultimately, these difficulties result in feelings of loneliness (Bauminger et al. 2003). In the typical population, use of the Internet, and specifically, social media, has been found to enhance friendship quality, increase social interactions and minimise feelings of 
loneliness (Valkenburg and Peter 2007). Thus, it may be that individuals with WS or ASD who have the intellectual ability to access the internet use this platform as a means of seeking out the social relationships that they lack in their offline world. Mazurek (2013) offered the first findings on social media use among adults with ASD, finding that around $80 \%$ used social networking sites, with 'forming social connections' being the most common reason for engaging in this activity. Content analysis of the data revealed that many individuals with ASD acknowledged that they used social media as an alternative way to try and engage with others. Heightened loneliness may result in an exaggerated desire to establish friendships online, which could result in the risk-taking behaviour described earlier, meaning these individuals could be facing an elevated level of online social vulnerability, in comparison to their typically developing age-matched peers. This is particularly pertinent as the European Online Grooming Project et al. (2012) reported that offenders seek out loneliness and the subsequent desire for attention when selecting their victims, and successively exploit this to groom the individual online.

\section{Mental Health Problems}

Mental health problems have also been linked to enhanced vulnerability (European Online Grooming Project et al. 2012). Those experiencing depression or loneliness may be more motivated to seek solace in contacting strangers online (Wolak et al. 2004), and likewise, those with anxiety may feel protected by the diminished social presence that they usually struggle with, providing social stimulation without much of the social anxiety (Tian 2013). This is of particular significance when considering the online vulnerability of individuals with ASD, as a recent meta-analysis estimated that anxiety disorders were present in around $40 \%$ of children with ASD (van Steensel et al. 2012). Thus, social networking could provide these individuals with a platform to communicate with minimal anxiety; particularly reduced social evaluation and social anxiety. Similarly, anxiety has been noted in individuals with WS as one of the most common mental health challenges (Stinton et al. 2010). Recent findings by Riby et al. (2013a, b) found that higher anxiety levels were linked to more severe impairments in social functioning, which could be used as a possible explanation of why over $70 \%$ of adults with WS experience social isolation (Davies et al. 1998). As a result, those with mental health problems may be driven to gain social connectedness online to overcome their social isolation. Research into this triangular relationship between mental health, social isolation and vulnerable presentation online in individuals with developmental disorders would offer much needed information on the impact and intensity of this relationship.

\section{Disinhibition}

When deciding how to present ourselves in both online and offline worlds, it may be necessary for us to use attentional control and execute planning behaviours-for example, restraining and inhibiting impulsive behaviours that might have negative longer-term consequences. Indeed it has previously been proposed that some of the deficits of executive and inhibitory control associated with WS (e.g. Rhodes et al. 2010; Greer et al. 2013) could play a role in disinhibited social approach behaviours towards unfamiliar people (e.g. Little et al. 2013). Again it is unclear whether this may also relate to online social behaviours and the nature of information presented by an individual with WS or indeed with ASD due to the similar association between the disorder and attention and executive control deficits (e.g. see Kenworthy et al. 2010 for a review). Again, this is an avenue for debate and research attention.

\section{Discussion}

It is argued that if real-world vulnerability can be used as a predictor for online conduct and subsequent online vulnerability, then, individuals with developmental disorders, as illustrated by the cases of ASD and WS, could be facing a high level of risk when interacting with others via the internet (Livingstone et al. 2011). This is supported by similar trends for transference in the typically developing literature (Whittle et al. 2013b), as well as the social phenotypes associated with ASD and WS. If individuals with ASD express a desire to form social connectedness (Mazurek 2013), are unable to achieve this in the offline world (Chamberlain et al. 2007) and they are frequent users of screen based technology (Mazurek and Wenstrup 2013), it would be reasonable to assume that this pursuit online combined with their lack of social awareness could be placing them in a vulnerable position online. Similarly, we know that individuals with WS harbour an extreme pro-social drive to interact with others, both familiar and unfamiliar (Järvinen et al. 2013), yet experience difficulty in forming and maintaining these relationships in the offline environment (Jawaid et al. 2012). Therefore, the online platform provides a novel way to interact with others, with minimised anxiety due to lack of physical presence, and this could combine with their lack of social awareness to place them in an extremely vulnerable position online. Whilst we are not suggesting that all individuals with WS and ASD who engage in online interactions will be exploited or will be vulnerable, we do need to acknowledge that there may be risk factors that need to be taken into consideration and targeted for increased awareness and/or intervention. It is suggested that these suppositions do not just 
ring true for ASD and WS, but other individuals with developmental disorders who present as vulnerable in the offline world could be facing unprecedented online risks during their computer time. Whilst these prepositions currently remain provisional, we would argue that they follow a logical theoretical rationale to suggest that there is a serious issue of online vulnerability in individuals with developmental disorders that is currently being ignored by the literature.

Although it has been preliminarily reported that some individuals with developmental disorders use the internet as frequently as their typically developing peers (Mazurek 2013), the first step in addressing the aforementioned void should be to extend such research to gain more information on the level of Internet usage among young people with developmental disorders. This call for research will stimulate questions on issues such as the type of usage, level of supervision whilst online, and whether there is an interaction between Internet use, IQ and vulnerability. Such research would constitute the first stage in enhancing our knowledge with a view to informing an intervention needs that could help keep vulnerable individuals safer online.

Conflict of Interest The authors report no conflict of interest

\section{References}

American Psychiatric Association (2000). Diagnostic and statistical manual of mental disorders (4th ed., text rev.). Washington, DC.

Bauminger, N., Shulman, C., \& Agam, G. (2003). Peer interaction and loneliness in high-functioning children with autism. Journal of Autism and Developmental Disorders, 33, 489-507.

Billstedt, E., Gillberg, C., \& Gillberg, C. (2005). Autism after adolescence: population-based 13- to 22-year follow-up study of 120 individuals with autism diagnosed in childhood. Journal of Autism and Developmental Disorders, 35, 351-360.

Blum, R. W., McNeely, C., \& Nonnemaker, J. (2002). Vulnerability, risk, and protection. Journal of Adolescent Health, 31S, 28-39.

Chamberlain, B., Kasari, C., \& Rotheram-Fuller, E. (2007). Involvement or isolation? The social networks of children with autism in regular classrooms. Journal of Autism and Developmental Disorders, 37, 230-242.

Child Exploitation and Online Protection Centre (2010). Strategic overview 2009-2010. Retrieved November 1, 2013 via: http://www. ccinform.co.uk/articles/2010/11/05/5359/child+exploitation+and+ online+ protection+centre+strategic +overview.html.

Craven, S., Brown, S., \& Gilchrist, E. (2006). Sexual grooming of children: review of literature and theoretical considerations. Journal of Sexual Aggression, 12, 287-299.

Davies, M., Udwin, O., \& Howlin, P. (1998). Adults with Williams syndrome. Preliminary study of social, emotional and behavioural difficulties. British Journal of Psychiatry, 172, 273-276.

Dixon, L., Browne, K., \& Hamilton-Giachritsis, C. (2009). Patterns of risk and protective factors in the intergenerational cycle of maltreatment. Journal of Family Violence, 24, 111-122.

European Commission (2008). Towards a safer use of the internet for children in the EU-A parents' perspective: Analytical report. Flash Eurobarometer 248-The Gallup Organisation.
European Online Grooming Project: Webster, S., Davidson, J., Bifulco, A., Gottschalk, P., Caretti, V., Pham, T., \& Grove-Hills, J. (2012). European Online Grooming Project final report. Retrieved October 312013 via: http://www.natcen.ac.uk/media/22514/europeanonline-grooming-projectfinalreport.pdf.

Fisher, M. (2013). Evaluation of a stranger safety training programme for adults with Williams syndrome. Journal of Intellectual Disability Research. doi:10.1111/jir.12108.

Fisher, M., Moskowitz, A., \& Hodapp, R. (2012). Vulnerability and experience related to social victimization among individuals with intellectual and developmental disabilities. Journal of Mental Health Research in Intellectual Disabilities, 5, 32-48.

Fisher, M., Moskowitz, A., \& Hodapp, R. (2013). Differences in social vulnerability among individuals with autism spectrum disorder, Williams syndrome, and Down syndrome. Research in Autism Spectrum Disorders, 7, 931-937.

Fox, C. L., \& Boulton, M. J. (2005). The social skills problems of victims of bullying: self, peer and teacher perceptions. British Journal of Educational Psychology, 75, 313-328.

Frigerio, E., Burt, D. M., Gagliardi, C., Cioffi, G., Martelli, S., Perrett, D. I., et al. (2006). Is everybody always my friend? Perception of approachability in Williams syndrome. Neuropsychologia, 44, 254-259.

Greer, J., Riby, D., Hamiliton, C., \& Riby, L. (2013). Attentional lapse and inhibition control in adults with Williams syndrome. Research in Developmental Disabilities, 34, 4170-4177.

Hanley, M., Riby, D., Caswell, S., Rooney, S., \& Back, E. (2013). Looking and thinking: how individuals with Williams syndrome make judgements about mental states. Research in Developmental Disabilities, 34, 4466-4476.

Happé, F. (1999). Autism: cognitive deficit or cognitive style? Trends in Cognitive Science, 3(6), 216-222.

Hillier, L., Fulton, R., Fulton, L., Graves, T., Pepin, K., WagnerMcPherson, C., et al. (2003). The DNA sequence of human chromosome. Nature, 7(424), 157-164.

Hofvander, B., Delorme, R., Chaste, P., Nyden, A., Wentz, E., Stahlberg, O., et al. (2009). Psychiatric and psychosocial problems in adults with normal-intelligence autism spectrum disorders. $B M C$ Psychiatry, 9(35), 9-35.

Howlin, P., Goode, S., Hutton, J., \& Rutter, M. (2004). Adult outcome for children with autism. Journal of Child Psychology and Psychiatry, 45, 212-229.

Järvinen, A., Korenberg, J. R., \& Bellugi, U. (2013). The social phenotype of Williams syndrome. Current Opinion in Neurobiology, 23, 414-422.

Jawaid, A., Riby, D., Owens, J., White, S., Tarar, T., \& Schulz, P. (2012). 'Too withdrawn' or 'too friendly': considering social vulnerability in two neuro-developmental disorders. Journal of Intellectual Disability Research, 56(4), 335-350.

Jones, W., Bellugi, U., Lai, Z., Chiles, M., Reilly, J., Lincoln, A., \& Adolphs, R. (2000). Hypersociability in Williams syndrome. Journal of Cognitive Neuroscience, 12, 30-46.

Kenworthy, L., Yerys, B., Anthony, L., \& Wallace, G. L. (2010). Understanding executive control in autism spectrum disorders in the lab and in the real world. Neuropsychology Review, 18(4), 320 338.

Little, K., Riby, D., Janes, E., Clark, F., Fleck, R., \& Rodgers, J. (2013). Heterogeneity of social approach behaviour in Williams syndrome: the role of response inhibition. Research in Developmental Disabilities, 34, 959-967.

Livingstone, S., \& Bober, M. (2005). UK children go online. Swindon: Economic and Social Research Council (ESRC).

Livingstone, S., Haddon, L., Görzig, A., Olafsson, K. (2011). EU kids online September 2011. Retrieved on 31st October 2013 via: www2. lse.ac.uk/media@lse/research/EUKidsOnline/EU\%20kids\%2011\% 20(2009-11)/EUKidsOnlineIIIReports/Final\%20report.pdf. 
Masten, A. S., \& Powell, J. L. (2003). A resilience framework for research, policy and practice. In S. S. Luthar (Ed.), Resilience and vulnerability: Adaptation in the context of childhood adversities. New York: Cambridge University Press.

Mazurek, M. O. (2013). Social media use among adults with autism spectrum disorders. Computers in Human Behavior, 29, 1709-1714.

Mazurek, M., \& Wenstrup, C. (2013). Television, video game and social media use among children with ASD and typically developing siblings. Journal of Autism and Developmental Disorders, 43, $1258-1271$.

Mervis, C., Robinson, B., Bertrand, J., Morris, C., Klein-Tasman, B., \& Armstrong, S. (2000). The Williams syndrome cognitive profile. Brain and Cognition, 44, 604-628.

Mesch, G. (2001). Social relationships and Internet use among adolescents in Israel. Social Science Quarterly, 82, 329-340.

Mitchell, K. J., Ybarra, M., \& Finkelhor, D. (2007). The relative importance of online victimization in understanding depression, delinquency and substance use. Child Maltreatment, 12, 314-324.

Mitchell, K. J., Jones, L. M., Finkelhor, D., \& Wolak, J. (2011). Internetfacilitated commercial sexual exploitation of children: findings from a nationally representative sample of law enforcement agencies in the United States. Sexual Abuse: A Journal of Research and Treatment, 23, 43-71.

O'Leary, P. J., \& Barber, J. (2008). Gender differences in silencing following childhood sexual abuse. Journal of Child Sexual Abuse: Research, Treatment, and Program Innovations for Victims, Survivors, and Offenders, 17, 133-143.

Ofcom (2010). UK children's media literacy. Retrieved October 30, 2013 via: http://stakeholders.ofcom.org.uk/binaries/research/medialiteracy/ukchildrensml1.pdf.

Olson, L. N., Daggs, J. L., Ellevold, B. L., \& Rogers, T. K. (2007). Entrapping the innocent: toward a theory of child sexual predators' luring communication. Communication Theory, 17, 231-251.

Pinheiro, A., Galdo-Alvarez, S., Rauber, A., Sampaio, A., Niznikiewicz, M., \& Gonçalves, O. (2011). Abnormal processing of emotional prosody in Williams syndrome: an event-related potentials study. Research in Developmental Disability, 32, 133-147.

Pinkham, A. E., Hopfinger, J. B., Pelphrey, K. A., Piven, J., \& Penn, D. L. (2008). Neural bases for impaired social cognition in schizophrenia and autism spectrum disorders. Schizophrenia Research, 99, 164 175

Rhodes, S., Park, J., Fraser, E., \& Campbell, L. (2010). Executive neuropsychological functioning in individuals with Williams syndrome. Neuropsychologia, 48(5), 1216-1226.

Riby, D., \& Hancock, P. (2008). Viewing it differently: social scene perception in Williams syndrome and autism. Neuropsychologia, $46,2855-2860$

Riby, D., Hanley, M., Kirk, H., Clark, F., Little, K., Fleck, R., et al. (2013a). The interplay between anxiety and social functioning in Williams syndrome. Journal of Autism and Developmental Disorders, 13, 1984-1987.
Riby, D. M., Kirk, H., Hanley, M., \& Riby, L. M. (2013b). Stranger danger awareness in Williams syndrome. Journal of Intellectual Disability Research. doi:10.1111/jir.12055.

Rump, K., Giovannelli, J., Minshew, N., \& Strauss, M. (2009). The development of emotion recognition in individuals with autism. Child Development, 80(5), 1434-1447.

Searcy, Y. M., Lincoln, A., Rose, F., Klima, E., Bavar, N., \& Korenberg, J. R. (2004). The relationship between age and IQ in adults with Williams syndrome. American Journal on Mental Retardation, 109, 231-236.

Sidebotham, P. (2013). Culpability, vulnerability, agency and potential: exploring our attitudes to victims and perpetrators of abuse. Child Abuse Review, 22, 151-154.

Smith, M. J., Montagne, B., Perrett, D. I., Gill, M., \& Gallagher, L. (2010). Detecting subtle facial emotion recognition deficits in high-functioning autism using dynamic stimuli of varying intensities. Neuropsychologia, 48, 2777-2781.

Stinton, C., Elison, S., \& Howlin, P. (2010). Mental health problems in adults with Williams syndrome. American Journal on Intellectual and Developmental Disabilities, 115, 3-18.

Suler, J. (2004). The online disinhibition effect. Cyberpsychology \& Behavior, 7, 321-326.

Sullivan, K., Winner, E., \& Tager-Flusberg, H. (2003). Can adolescents with Williams syndrome tell the difference between lies and jokes? Developmental Neuropsychology, 23(1\&2), 85-103.

Talbot, N., Duberstein, P. R., Butzel, J. S., Cox, C., \& Giles, D. E. (2003). Personality traits and symptom reduction in a group treatment for women with histories of childhood sexual abuse. Comprehensive Psychiatry, 44(6), 448-453.

Tian, Q. (2013). Social anxiety, motivation, self-disclosure, and computer-mediated friendship: a path analysis of the social interaction in the blogosphere. Communication Research, 40(2), 237-260.

Valkenburg, P. M., \& Peter, J. (2007). Preadolescents' and adolescents' online communication and their closeness to friends. Developmental Psychology, 43, 267-277.

van Steensel, F., Bögels, S., \& Dirksen, C. (2012). Anxiety and quality of life: clinically anxious children with and without autism spectrum disorders compared. Journal of Clinical Child \& Adolescent Psychology, 41(6), 731-738.

Whittle, H., Hamilton-Giachritsis, C., Beech, A., \& Collings, G. (2013a). A review of online grooming: characteristics and concerns. Aggression and Violent Behavior, 18, 62-70.

Whittle, H., Hamilton-Giachritsis, C., Beech, A., \& Collings, G. (2013b). A review of young people's vulnerabilities to online grooming. Aggression and Violent Behavior, 18, 135-146.

Willis, J., \& Todorov, A. (2006). First impressions: making up your mind after $100 \mathrm{~ms}$ exposure to a face. Psychological Science, 17, 592598.

Wolak, J., Finkelhor, D., \& Mitchell, K. J. (2004). Internet-initiated sex crimes against minors: implications for prevention based on findings from a national study. Journal of Adolescent Health, 35, 424.e11424.e20. 